\title{
3
}

\section{What does data sovereignty imply: what does it look like?}

\author{
C Matthew Snipp
}

Indigenous people have long struggled to retain their rights as autonomous self-governing people. These struggles have sometimes involved litigation, sometimes political manoeuvring and, too often, violence and bloodshed. In the United States, for example, various groups of native people waged war against Europeans virtually from the early days of first contact in the sixteenth century until the last battle was fought with the US Army in 1890. In the twentyfirst century, another form of aboriginal sovereignty is at stake: data sovereignty.

\section{Defining data sovereignty}

The term 'data sovereignty' is a uniquely twenty-first-century expression that arises directly from the explosive growth of information associated with the internet and the spread of mobile phone technology. Quite simply, data sovereignty means managing information in a way that is consistent with the laws, practices and customs of the nation-state in which it is located. Privacy laws, for example, vary from one country to another. In recognition of the variability, data sovereignty means that information that would be illegal to provide in one location might be perfectly legal to 
disclose in another nation. In 2010, the search engine Google became famously embroiled in a controversy with Chinese authorities over their censorship practices. Google executives were loath to allow the Chinese Government to censor search results and to access email accounts managed by the company. This led the company to move its offices to Hong Kong and caused them to cede the large and lucrative Chinese market to their competitor Baidu.com (Helft \& Barboza 2010).

The Chinese example notwithstanding, vast amounts of data are now accessible from virtually any far-flung part of the world. Geographic boundaries that once impeded the flow of information from one location to another are largely irrelevant. In the twentieth century, shutting down radio and television broadcasts and disabling telephone services across physical landlines could easily limit access to information. By comparison, mobile phone technology, satellite phones and internet access make the control of information vastly more difficult for smaller nations with resources more limited than the Government of China and a handful of other large, powerful and wealthy nations such as the United States. These smaller and less wealthy nations of course include indigenous people. There are vast differences among these groups in their size, their wealth and especially their powers as sovereign entities. However, suffice to say, in all instances, they are smaller, poorer and weaker than the settler states that typically surround them.

That indigenous people are typically poorer than the surrounding settler state has important implications for data sovereignty. This is because collecting data that can be turned into information and later organised into meaningful knowledge is a costly process. Censuses and surveys are very costly to conduct and even unobtrusive video surveillance must be processed to condense it and make it intelligible. This, too, often means that indigenous communities must forgo having access to certain types of information about themselves or must rely on outsiders with the requisite resources to obtain this information. of course, relying on outsiders typically involves significant compromises over the control of data and therefore data sovereignty. Thus, these compromises entail important questions about from whom data are collected, the content of these data, the purposes for which these data are to be used and who will ultimately control access to these data. These questions are critical for understanding the vestiges of colonial dependency of indigenous people on the settler state. 


\section{Data from whom?}

Before the collection of data can begin, a fundamental question must be asked - and answered - and that is: from whom will information be obtained? This is not a trivial question because it defines the universe and sampling frame for surveys, the subjects eligible to participate in experiments and who will and will not be counted in a census, just to name a few examples. For the purpose of collecting data from indigenous people, this question invokes the deeply complex question of 'who is (and is not) indigenous?'

\section{Defining indigeneity}

The question of 'who is indigenous' is deeply complex because it involves issues that must be addressed simultaneously and independently. On one hand, indigeneity is a group characteristic that defines the qualities of a collectivity. On the other hand, it is also a personal characteristic that either binds together or sets apart individuals from the larger collective of people deemed to be 'indigenous'. The experience of American Indians in the United States provides a good example of this duality, and it is a simpler example than in other parts of the world. For instance, in the United States, indigeneity is defined by the presence of ancestors occupying this part of the Western Hemisphere prior to 1492. In contrast, indigeneity in other continents such as Asia or Africa might hearken back to the earliest presence of Homo sapiens, long before recorded knowledge. Needless to say, this makes indigeneity virtually impossible to establish. So, for the sake of convenience in these regions, indigeneity simply means a presence prior to the arrival of European colonists, thereby making colonial contact one of the hallmarks of indigeneity everywhere in the world. Smith (1999) describes this as research through 'imperial eyes'.

Although 1492 benchmarks indigeneity in the Western Hemisphere, the settler states that now occupy and control this region typically complicate indigeneity with their own views of who is and is not indigenous. In Mexico, for example, a person is not indigenous unless they are capable of speaking an indigenous language such as Zapotec. In the United States, the federal government and the Congress in particular have determined that an American Indian is 
any person who belongs to a federally recognised tribe. Returning to the aforementioned duality of indigeneity, this begs the questions of what constitutes a 'federally recognised tribe' and how does one 'belong' to such an entity? The latter question has a very direct bearing on data sovereignty because the US Supreme Court has ruled that a determination of who 'belongs' to a tribe is a fundamental right that inheres in the political sovereignty of the tribes themselves. That is, in the Supreme Court decision of Santa Clara Pueblo v. Martinez (436 US 49 [1978]), the justices reasoned that by their retained rights of self-government, the ability of the tribes to determine what conditions must be met to qualify for tribal membership was a fundamental part of their sovereign powers. Although the court ruled that tribes may determine the conditions of membership, and there is a plethora of different conditions for different tribes, the court has not ruled on what constitutes a federally recognised tribe (Lerma 2014).

Instead, the legislative and executive branches of the federal government have taken a more active role in this determination. A complete account of how tribes have gained federal recognition is beyond the scope of this essay. However, several details are worth noting in relation to data sovereignty and especially for the determination of indigeneity.

Most tribes have received federal recognition by dint of their resistance to the expansion of the United States in the eighteenth and nineteenth centuries. This resistance led to treaties and other agreements that bestowed federal recognition. However, there also were many tribes that were too small to resist or simply acquiesced to the presence of American settlers and their demands for land. The existence of such groups was belatedly acknowledged in 1978 when the Bureau of Indian Affairs set forth a process for heretofore 'unrecognised tribes' to gain federal recognition. At that time, 356 groups requested federal recognition (BIA 2013). However, as of late 2013, only 17 of these cases had been resolved and granted federal recognition. Another nine were granted recognition by acts of Congress. Thirty-four petitions were denied and the remainder are still pending in review.

There is a multiplicity of conditions that the tribes may impose for membership. Frequently, there is some sort of descent requirement that establishes a minimum amount of American Indian heritage as measured by 'blood quantum'. Full-blood quantum indicates a fully 
indigenous maternal and paternal heritage. One-quarter blood quantum is a common standard that was first established by the Bureau of Indian Affairs (BIA) in 1933 and has been widely adopted by tribal governments. One way of thinking about this requirement is that it involves being able to document having one full-blood grandparent if the remaining grandparents are not indigenous. Political theorist Will Kymlicka (1995: 23) argues that such rules are fundamentally racist and manifestly unjust. Still, these rules remain widely accepted by a large number of American Indian tribes.

Returning to the subject of data sovereignty, it should be clear that the matter of from whom data should be collected is bound up in legal principles and bureaucratic regulations connected with the sovereign political rights of indigenous people. One might imagine that having established these elaborate edifices, the US Government would be assiduously cognisant of them whenever data are to be solicited from American Indians. One would be very wrong to make this assumption.

The US Census Bureau is the single largest and most comprehensive source of information about American Indians and Alaska Natives, as well as Native Hawaiians. ${ }^{1}$ This information is collected in conjunction with the decennial census and a very large survey known as the American Community Survey. The Census Bureau embeds categories of indigeneity within its question about racial heritage - the same question used to identify other racial groups in American society. It takes virtually no heed whatsoever of the sovereign political status of American Indians beyond an instruction to 'print principal or enrolled tribe' for persons who indicate they are American Indians. Persons who do not report a tribe are tabulated simply as 'Tribe not reported', and about 20 per cent of persons reporting to be an American Indian did not report a tribe in 2010 (Liebler \& Zacher 2013).

The tribes would have it otherwise. The author of this essay spent over nine years on a committee established by the Census Bureau to offer advice on how the bureau collects and disseminates information about race and ethnicity. The American Indians on this committee repeatedly requested the Census Bureau pay greater heed to enrolment status than

1 The legal and political status of Alaska Natives is slightly different to that of American Indians. The legal and political status of Native Hawaiians is substantially different to that of the other two groups. 
a vague instruction by adding a question about enrolment status or clarifying the meaning of 'enrolment'. ${ }^{2}$ The Census Bureau steadfastly refused these requests, usually citing insufficient questionnaire space for an additional question or instructions. Verifying enrolment or conducting follow-up contacts with persons who did not report a tribe were dismissed out of hand as too costly. ${ }^{3}$

\section{Data dissemination}

The US Census Bureau does not entirely disregard the sovereign status of American Indian tribes but it is only an afterthought in the dissemination of data, not in its collection. That is, the Census Bureau does publish data for geographic areas specifically identified with American Indians - that is, reservations. It also works with tribal communities living in areas where there is some other geographic connection, such as Alaska Native villages or the former Indian Territory known today as the state of Oklahoma. In fact, there is a substantial list of geographic units recognised by the Census Bureau:

- Alaska Native Village Statistical Areas (ANVSAs)

- Alaska Native Regional Corporations (ANRCs)

- Oklahoma Tribal Statistical Areas (OTSAs)

- OTSA Tribal Subdivisions

- Tribal Designated Statistical Areas (TDSAs)

- Tribal Census Tracts and Tribal Block Groups (on federally recognised reservations only)

- State American Indian Reservations (SAIRs)

- State Designated Tribal Statistical Areas (SDTSAs).

Missing from this, however, are cities where the majority of American Indians now reside. One reason for this omission is that, in most cities, with the exception of Minneapolis, American Indians are not clustered in ethnic enclaves like other minorities. Nonetheless, the fact that the Census Bureau pays little heed to tribal enrolment, and only incidental

2 To date, the Census Bureau has never defined, much less clarified, the meaning of 'principal tribe'.

3 In 2017, the Census Bureau will field test a tribal enrolment question but this will be too late to be incorporated into the 2020 census. However, it may possibly inform thinking about questionnaire construction in the American Community Survey and the 2030 census. 
attention to American Indians in urban areas, means that tribes do not have a precise accounting of their membership. This is also because many census-identified American Indians (especially in cities) do not claim tribal citizenship. As a result, there is a substantial mismatch between the numbers of American Indians counted in the census and the enrolment number reported by the tribes. For example, in 2001, the BIA reported there were 1,816,504 enrolled tribal members. ${ }^{4}$ A year earlier, the Census Bureau enumerated 4.1 million persons who were identified as American Indians and/or Alaska Natives in the 2000 census. $^{5}$

While it is true that tribes could initiate their own data collection efforts and determine for themselves from whom data were obtained, censuses and surveys are expensive and tribal communities typically lack the resources and expertise to mount such operations. Administrative data can sometimes be deployed for some purposes, but, again, this type of information can often be difficult to repurpose for other applications and may be incomplete and subject to clerical errors and related problems. And, again, it misses completely those persons residing away from tribal lands.

Although this discussion has focused almost exclusively on the American Indian experience in the United States, it should be remembered that similar accounting difficulties exist around the world wherever indigenous people are located. As Davis (this volume) reminds us, there is perhaps no better illustration of these difficulties than the challenge faced by Martinez Cobo as he struggled with a working definition of who might be covered by the United Nations Declaration on the Rights of Indigenous Peoples (UNDRIP). In spite of the apparent specificity of conditions laid, the prevailing view today is that no formal universal definition of the term is necessary and, for practical purposes, the understanding of the term commonly accepted is the one provided by Martinez Cobo (UN 2004: 4).

\footnotetext{
$4 \quad$ The BIA issues biennial reports. The preceding report was issued in 1999.

5 The discrepancy in these numbers and in earlier BIA reports led to a review of and long hiatus in the reports. The BIA stopped issuing these reports after 2005 and renewed their publication in 2013, using census data instead to produce their estimates.
} 


\section{Data about what and for what?}

\section{Data content}

Assuming there is some agreement about from whom data are to be obtained, there is the next matter of the content domains connected with the data. These domains may vary a great deal depending on the uses for which the data are intended, while their purpose may also vary depending on whether the end-user is the indigenous community or the settler state. Again, the experiences of American Indians in the United States are instructive.

Whether indigenous communities or agencies of settler states collect data likely makes a vast difference to the content of that data. Needless to say, the motivations for data collection by settler states are often vastly different than those behind data collection by indigenous communities. Settler states may be motivated by the perceived need to monitor and exercise surveillance over indigenous communities. In some cases, this surveillance may be for law enforcement or military purposes. In other instances, this surveillance may be more benign and involve data collection for the provision of social services or other forms of community development.

On the other hand, indigenous communities may wish to take stock of their communities for purposes that are rather different to those of the settler state. Indeed, access to and control of data for indigenous communities are two means of exercising a measure of autonomy and independence from surrounding settler states. Indigenous communities may wish to assess the specific needs of their community, especially when outside authorities are willing to provide no more than nonspecific aggregate information. This kind of information can be invaluable for the purpose of planning community development projects and making the case for certain types of assistance from outside authorities and nongovernmental organisations (NGOs). Indigenous communities also might seek more intangible sorts of information such as community attitudes, which might concern the desirability of projects such as bridge construction or even more volatile matters such as political beliefs (Clifford 2013). 
In the United States, American Indian tribes typically lack the resources to routinely collect data of any description, especially the sort that can be obtained from surveys or censuses. Many tribes do, however, collect information in the course of delivering services of one sort or another, such as housing assistance, job training or social services. However, this information typically pertains to only the most needy tribal members. In some instances, data obtained from the US Census Bureau provide baseline information about education, employment, income and similar characteristics for the geographic units described above. However, the Census Bureau routinely refuses to provide data for geographical areas smaller than the ones already listed. ${ }^{6}$ Furthermore, the Census Bureau has steadfastly refused to collect information it regards as 'subjective' attitudinal data. Consequently, for tribes to obtain information about community attitudes, they must either obtain financial resources elsewhere or rely on the traditional sources of rumour and hearsay.

For other minorities - such as African Americans, Asians and Hispanics - there are national polls and surveys that produce a great deal of information about the attitudes, beliefs and even mental health of these groups. The National Survey of Black Americans, for example, included questions about their use of mental health services and their religious commitment. The Latino National Survey conducted in 2006 asked questions about ethnic identity and political ideology. A comparable survey of American Indians and Alaska Natives has never been conducted in the United States. While a national survey of American Indians would not yield tribe or community-specific information, such a survey might nonetheless be informative about a broad range of issues affecting American Indians, especially compared with other groups in American society.

One likely reason that a national survey of American Indians has not been undertaken is logistics. Outside tribal lands, locating and surveying American Indians are challenging using conventional survey methods. American Indians and Alaska Natives make up slightly less than 2 per cent of the total US population. In addition, outside tribal lands, they tend not to live in large residential clusters like African Americans and Hispanics. Unlike other minority groups, they are not

6 The Census Bureau refuses such requests citing the protection of data confidentiality as the reason. More will be said about this issue below. 
residentially segregated, although they are spread throughout poor and working-class neighbourhoods. Using conventional sampling frames means that very large numbers of respondents must be contacted and screened to obtain a sample of sufficient size and power to yield informative results. Needless to say, this is prohibitively costly. Put another way, assuming a 50 per cent response rate, it would take about 100,000 calls to obtain a sample with 9,000 respondents.

\section{Privacy and confidentiality}

Fielding a national survey of indigenous people, such as the National Aboriginal and Torres Strait Islander Social Survey in Australia (see Jelfs, this volume), would be a very significant development for American Indians. However, the content of these sorts of surveys, along with the typically small size of most indigenous communities, raises other concerns - namely, those connected with the privacy and confidentiality of the data. Privacy and confidentiality are fundamental issues connected with data sovereignty because settler states and indigenous communities alike may have laws and regulations designed to manage the privacy and confidentiality of data, especially personally identifiable data. Furthermore, there may be public attitudes and expectations associated with data for indigenous people.

Concerns about 'privacy' speak to the data content that is collected from individuals. Information that is considered 'private' frequently includes financial and health information, but, in the case of indigenous communities, it may involve other sorts of activities such as participation in religious and other ceremonies, hunting and gathering practices or support for community development projects. While this information might be invaluable for tribal leaders, academics and others lacking a vested interest in these activities, collecting this information may be viewed as intrusive at a minimum or even threatening and potentially harmful. The leaders of indigenous communities are often mindful of privacy concerns and may be in a position to prevent intrusive data collection. Some American Indian communities have established institutional review boards (IRBs) that must approve a project before research can be carried out in their communities.

However, these boards are no guarantee that data, once collected, will not be shared with others for unauthorised purposes. In one notable instance, the Havasupai tribe in Arizona shared blood samples in 
1990 with researchers from Arizona State University interested in using this material for diabetes research. However, the DNA extracted from this blood was widely shared with other researchers with little or no interest in diabetes. According to a story that appeared in The New York Times, 'their blood samples had been used to study many other things, including mental illness and theories of the tribe's geographical origins that contradict their traditional stories' (Harmon 2010). The tribe eventually won a lawsuit that ordered a return of the blood samples and halted further research with them, along with a punitive damages award of US $\$ 700,000$ that was paid by the university. However, the scientist who originally obtained these samples insisted that she did nothing wrong by sharing them with colleagues and maintained this position even after the courts sided with the tribe.

While concerns about privacy relate to the collection of information, confidentiality relates to how data are managed after they are collected - especially when respondents are promised anonymity in exchange for their cooperation. In the United States, data collected by the federal government are typically regarded as confidential except in the instance where they are considered a matter of public record such as in government budgets. Title 13 of the US Code compels individuals to respond to the decennial census and the American Community Survey, but it also imposes strict penalties on Census Bureau employees who disclose personally identifiable information. Similarly, the Confidential Information Protection and Statistical Efficiency Act ${ }^{7}$ enacted in 2002 provides broad protections of confidentiality across all federal statistics agencies.

While the US federal government vigilantly protects the confidentiality of respondents from whom it collects information, this vigilance does not always serve the purposes of tribal communities who wish to use these data. The litmus test used by federal agencies before publishing data is a determination about whether the data are personally identifiable through 'deductive disclosure'. Deductive disclosure means that personal characteristics can be combined in a way that associates them with specific individuals. For instance, there might be only one Native Hawaiian living in the town of Dubuque, Iowa

7 Confidential Information Protection and Statistical Efficiency Act, Public Law 107-347, 116 Stat. 2899, 44 USC $§ 101$. 
(a small town in the American Midwest). If the Census Bureau then reports that the median personal income of Native Hawaiians living in Dubuque is $\$ 20,000$, anyone acquainted with this person who knows their ethnic identity also will know their personal income. Consequently, the Census Bureau and other federal statistics agencies routinely suppress information they deem deductively disclosable.

In most instances, this is a lawful and entirely reasonable practice. Nonetheless, it can be problematic for indigenous communities under the following circumstances. In small indigenous communities, tribal officials, for instance, may wish to demonstrate the prevalence of a particular problem - for example, that the income of every family in the community is below the official poverty threshold. However, it is frequently the case that income data for small communities are routinely suppressed due to concerns about deductive disclosure. While it is certainly desirable to show the extent of poverty in these places, it has to remain an article of faith because the data to empirically demonstrate this problem are routinely withheld by the Census Bureau. Small tribal communities may voluntarily offer their consent to have such information disclosed, but exceptions are not allowed under existing federal policies. Consequently, there is a great deal of data collected by the Census Bureau and other agencies, such as the Indian Health Service, that are not accessible to smaller tribal communities. Even large tribes may encounter this problem. The Navajo Nation, one of the largest tribes in the United States, is organised around units known as chapter houses. Data for chapter houses are virtually nonexistent because they are too small to meet thresholds imposed by the Census Bureau to avoid deductive disclosure.

\section{Technological solutions?}

Indigenous control of data collection and dissemination is the obvious solution to the problems enumerated above - that is, the essential problems associated with exercising data sovereignty entail indigenous people being in control of data content. This involves being able to dictate what information is collected under what circumstances and then being able to determine how it is used and for what purposes. However, it seems implausible that settler states will ever be willing to fully accommodate the interests of indigenous communities. Thus, tribal communities must be able to collect their 
own data or simply deal with the limits imposed by the settler state. For reasons already suggested, this simply has not been possible in the recent past. Data collection operations require a degree of expertise and, more importantly, financial resources beyond the means of most native communities. However, there are reasons this might change in the foreseeable future.

Growing access to the internet and the spread of mobile phone technology are two developments that tribal communities might be able to harness for data collection purposes. In many countries, mobile phone services cost less and provide better coverage than existing landlines. In some locations, the cost of the phone and the electricity to power it is a barrier to the use of this technology. Nonetheless, as a consequence of mobile phones, indigenous people are better connected to one another than at anytime in the past. Tribal governments and others wishing to obtain information from native people have an opportunity to use or develop applications that allow responses to be made on even the simplest and most inexpensive 'flip phones'. Literacy, of course, also may impede this approach, but it still presents an opportunity for indigenous people to obtain and control information that has not existed in the past.

Internet access represents a profoundly important tool for indigenous people and their communities to manage and share information, although access may be too costly in some places. However, once again, mobile phone technology can extend the reach of the internet. Furthermore, for those communities that have the internet within reach, it is a powerful tool for soliciting information from community members and for managing other sources of locally generated information. Even when an entire community lacks network access, it might be possible for local leaders to bridge this gap by creating shared access points in local schools, public libraries or kiosks in government offices. Developing the skills and talent needed to exploit technology is an urgent challenge that must be met. 


\section{Concluding comments: data sovereignty in a postcolonial world}

As long as settler states surround indigenous communities, it may make little sense to talk about a fully postcolonial world. In fact, UNDRIP defines indigeneity in its relationship to colonial contact. Nonetheless, thinking of postcolonialism as a continuum instead of a simple binary condition does make it possible to think about how native people might claim greater control of data connected to them. This is especially critical in a world where information is monetised and made increasingly important and increasingly valuable. So, what features would enhance the data sovereignty of indigenous people?

1. Perhaps the most significant feature of decolonised data would be the power of indigenous people to determine who should be counted among them - that is, indigenous communities should be empowered to determine who belongs among them and who should be excluded for the purposes of data collection. Historically, settler states have made this determination, but settler states have vested interests that may or likely may not coincide with the interests of native people.

2. The content of decolonised indigenous data must reflect the interests, values and priorities of native people. This is a statement that is much easier to make than to realise. Indigenous communities are seldom of one mind about any given issue and what one segment of the community deems important and valuable may be less important and less valuable to another faction of the community. Nonetheless, to the extent that there are core values that transcend narrower interests, these certainly must guide decisions that shape the content of indigenous data. Data that put individuals or the community at risk of personal or financial harm, for example, must be scrutinised carefully in terms of their value and utility, and handled accordingly.

3. Similar to the preceding point, tribal communities must not only dictate the content of data collected about them, they must also have the power to determine who has access to these data. This measure may seem redolent of censorship, but all governments and all communities possess data that are inappropriate for widespread disclosure. In the United States, financial transactions are usually 
considered private and immune to disclosure. Even the Government of the United States exercises a great deal of discretion over the data it collects, withholding some data from public access while disclosing others. For indigenous communities to have a degree of sovereignty over the data pertaining to them, they must act with the same authority.

It is one matter to make these points but another to bring them to fulfilment. Nonetheless, there are two mechanisms that may facilitate greater control over indigenous data. One is essential and the other is less essential but useful nonetheless. Expertise in the production and management of data of all types is absolutely essential. The ability to conduct surveys and censuses, manage and process administrative data and carry out qualitative fieldwork is essential for a community wishing to create and control its own data. Likewise, technical skills related to managing archives and websites, along with the networks and hardware necessary for these activities, are also essential. Historically, indigenous communities have been profoundly lacking in these capabilities; however, the cost and diffusion of this knowledge have declined dramatically in recent years, making it accessible to a wide variety of settings.

A second mechanism involves institutional oversight of research and data collection in indigenous communities. In the United States, universities and other organisations engaged in the collection of data have established IRBs to ensure ethical practices in research projects. These boards were established in the wake of highly controversial ethical breaches connected with academic research. However, some American Indian tribes have also established these boards whenever a research project is proposed to involve the tribe. As tribal people become more sophisticated about the importance and value of research in their communities, this may be one vehicle to prevent the exploitation of local knowledge, and to protect intellectual property such as that sought after by ethno-botanists.

These are but two measures that will enhance the sovereign control that indigenous people can wield over data and especially knowledge connected with indigeneity. There are a growing number of scholars addressing these issues, not least in the present volume, and particularly in regard to the deployment of research in indigenous communities (Smith 1999; Wilson 2009; Kovach 2010; Walter \& Andersen 2013; 
Lambert 2014). This small but growing literature promises to align academic research with the interests of native communities. Once this knowledge is produced, it is incumbent on native communities to exercise sovereignty over these data to which they are so richly entitled.

\section{References}

Bureau of Indian Affairs (BIA) (2013). Brief overview, Office of Federal Acknowledgement, 12 November, BIA, Washington, DC, bia.gov/cs/ groups/xofa/documents/text/idcl-024417.pdf.

Clifford J (2013). Returns: becoming indigenous in the 21st century, Harvard University Press, Cambridge, Mass.

Harmon A (2010). Tribe wins fight to limit research of its DNA. The New York Times, 10 April 2010, nytimes.com/2010/04/22/ us/22dna.html.

Helft M \& Barboza D (2010). Google shuts China site in dispute over censorship. The New York Times, [Technology], 22 March 2010, nytimes.com/2010/03/23/technology/23google.html.

Kovach M (2010). Indigenous methodologies: characteristics, conversations, and contexts, University of Toronto Press, Toronto.

Kymlicka W (1995). Multicultural citizenship: a liberal theory of minority rights, Oxford University Press, New York.

Lambert L (2014). Research for indigenous survival: indigenous research methodologies in the behavioral sciences, University of Nebraska Press for the Salish Kootenai College Press, Lincoln, Nebr.

Lerma M (2014). Indigenous sovereignty in the 21st century: knowledge for the indigenous spring, Florida Academic Press, Gainesville, Fla.

Liebler CA \& Zacher M (2013). American Indians without tribes in the 21st century. Ethnic and Racial Studies 36:1910-34.

Smith LT (1999). Decolonizing methodologies, Zed Books, New York. 
United Nations (UN) (2004). The concept of indigenous peoples, Workshop on data collection and disaggregation for indigenous peoples, United Nations Permanent Forum on Indigenous Issues, New York, 19-21 January 2004.

Walter M \& Andersen C (2013). Indigenous statistics: a quantitative research methodology, Left Coast Press, Walnut Creek, CA.

Wilson S (2009). Research is ceremony: indigenous research methods, Fernwood Publishing, Black Point, Nova Scotia. 
This text is taken from Indigenous Data Sovereignty: Toward an agenda, edited by Tahu Kukutai and John Taylor, published 2016 by ANU Press, The Australian National University, Canberra, Australia. 